\title{
Oxidative stress in colonic adenocarcinoma: An impact on the body's antioxidative status and oxidative protein damage
}

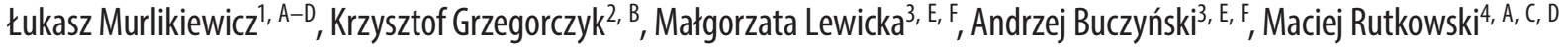 \\ 1 Department of General and Oncological Surgery, Regional Integrated Hospital, Płock, Poland \\ ${ }^{2}$ Department of Endoscopy and One Day Gastroenterology, Regional Specialist Hospital of dr Wł. Biegański in Łódź, Poland \\ ${ }^{3}$ Department of Epidemiology and Public Health, Medical University of Lodz, Poland \\ ${ }^{4}$ Department of Military Toxicology and Radiological Protection, Medical University of Lodz, Poland \\ A - research concept and design; $\mathrm{B}$ - collection and/or assembly of data; $\mathrm{C}$ - data analysis and interpretation; \\ $D$ - writing the article; $E$ - critical revision of the article; $F$ - final approval of the article
}

Address for correspondence

Małgorzata Lewicka

E-mail:malgorzata.lewicka@umed.lodz.pl

Funding sources

None declared

Conflict of interest

None declared

Received on January 29, 2016

Reviewed on July 6, 2016

Accepted on December 15, 2016

DOI

$10.17219 /$ acem/67819

\section{Copyright}

Copyright by Author(s)

This is an article distributed under the terms of the

Creative Commons Attribution Non-Commercial License

(http://creativecommons.org/licenses/by-nc-nd/4.0/)

\begin{abstract}
Background. Thus far, the pathogenesis of these intestinal tumors has not been fully explained. However, the analysis of risk factors and research regarding their formation that have continued for 3 decades have allowed us to demonstrate a significant role of oxidative stress in the processes leading to the development of cancer in the large intestine as well as in some other organs.
\end{abstract}

Objectives. The aim of the study was to examine the level of anti-oxidative status and the degree of oxidative protein damage in patients with varying severity of colonic adenocarcinoma (CAC) in relation to healthy individuals.

Material and methods. The study involved 4 groups (A-D) of patients with increasing severity of CAC stages according to Dukes' classification and a control group of healthy volunteers. Total antioxidant capacity (TAC) of blood plasma, as well as carbonyl $(C=0)$ group contents in blood plasma proteins as a product of their oxidative damage, were estimated in all participants. Both parameters were determined by spectrophotometric methods using commercial kit to test TAC and 2,4-dinitrophenylhydrazine to assay the contents of $C=0$ groups.

Results. In each of the studied groups, A-D, a statistically significant reduction in the TAC values was noted relative to the control group, which progressed with increased severity of CAC stages: $1.783 \mathrm{mmol} / \mathrm{L}$ vs $1.191 \mathrm{mmol} / \mathrm{L}$ (group A), $1.07 \mathrm{mmol} / \mathrm{L}$ (group B), $0.931 \mathrm{mmol} / \mathrm{L}$ (group C), and $0.899 \mathrm{mmol} / \mathrm{L}$ (group D). At the same time, significantly increased contents of protein $C=0$ groups were observed compared to the controls, also progressive in the course of growing CAC severity: $0.496 \mathrm{nmol} / \mathrm{mg}$ protein vs $0.57 \mathrm{nmol} / \mathrm{mg}$ protein (group A), $0.689 \mathrm{nmol} / \mathrm{mg}$ protein (group B), $0.804 \mathrm{nmol} / \mathrm{mg}$ protein (group C), and $1.054 \mathrm{nmol} / \mathrm{mg}$ protein (group D).

Conclusions. The CAC-related oxidative stress considerably reduces the systemic anti-oxidative status and increases the protein damage; both those changes become worse in parallel with the progression of this cancer.

Key words: oxidative stress, total antioxidant capacity, colonic adenocarcinoma, oxidative protein damage 


\section{Introduction}

Malignant tumors of the large intestine are one of the main subjects of research on neoplasms, as they are on the $3^{\text {rd }}$ top position in respect to morbidity and mortality rates, preceded only by breast cancer in women and lung cancer in men. ${ }^{1}$ This applies especially to their histologically dominating form ( $>95 \%)$, that is colonic adenocarcinoma (CAC), in $62 \%$ of cases located in the distal section of large intestine: sigmoid and rectum. ${ }^{2}$ Thus far, the pathogenesis of these intestinal tumors has not been fully explained. However, the analysis of risk factors and research on hypotheses of their formation that have continued for 3 decades have allowed us to demonstrate the significant role of the oxidative stress in the processes leading to the development of cancer in the large intestine as well as in some other organs.

Oxidative stress is the shifting of the body's oxido-reductive balance towards oxidative reaction, resulting from disorders of oxygen metabolism. ${ }^{3}$ Its main cause is the excessive production of reactive oxygen species (ROS), which are toxic to cells. It has been documented that oxidative stress participates in the formation and development of numerous diseases, including cancer. This is due to the fact that exposure of cells to excessive amounts of ROS causes damage to the structural cellular macromolecules: lipids, proteins, nucleic acids and carbohydrates, and this in turn leads to pathogenic dysfunctions of cells. ${ }^{4}$

The body possesses, however, an anti-oxidative defense system, which protects it against ROS. It includes some specialized enzymes, non-enzymatic antioxidants (e.g., glutathione, vitamins $\mathrm{C}, \mathrm{E}$ and many others), as well as some microelements. ${ }^{5}$ In diseases with the intensive production of ROS, that is with the intense oxidative stress, the defense system becomes significantly weaker due to the accelerated depletion of its elements. In consequence, the body is much more susceptible to the detrimental influence of ROS.

Determining the degree of intensity of oxidative stress in the related diseases is, therefore, clinically valuable, as it aids in the rational diagnosis as well as control over the progress in the treatment. For this purpose, it is possible to assay either concentrations of the most important elements of the body's anti-oxidative defense system or the products of reactions between ROS and the components of the cells.

However, the assay of even only the most important antioxidants is difficult and laborious, and in total simply unfeasible. Instead of this, while undertaking the below described research, it was decided to assay the total anti-oxidative capacity (TAC). This is an acknowledged measure of the oxido-reductive balance, well reflecting the anti-oxidative properties of complex biological systems existing in the human body, e.g., blood plasma. ${ }^{6}$ In order to simultaneously evaluate the destructive influence of ROS, it was decided to include in the research also the oxidative damage of proteins. This parameter was not as well tested as similar damages of lipids or DNA, even though proteins dominate among the elements of the human body with normal BMI (in obese subjects lipids are dominant and obesity is a risk factor for colon cancer). Therefore, the results of the respective tests relating to the proteins have special cognitive value. It is possible to assay 3 markers of damage of these fundamental macromolecules: the content of amino $\left(-\mathrm{NH}_{2}\right)$, thiol $(-\mathrm{SH})$ or carbonyl $(\mathrm{C}=\mathrm{O})$ groups. Because of the fact that the latter seems to be the best marker of oxidative stress, it was decided that it would be applied in our research reported in this paper.?

The aim of this work was, therefore, to assess the status of the anti-oxidative defense system (based on the TAC assays), as well as the oxidative damage of proteins (based on the assay of $\mathrm{C}=\mathrm{O}$ groups) in patients at various stages of CAC severity. At the same time, an attempt has been made to determine if there is any correlation between these 2 parameters.

\section{Material and methods}

\section{Patients}

The study group comprised 102 patients (42 women and 60 men; mean age for the entire group was $64.4 \pm 10.9$ years), who underwent surgery on the premises of our department due to adenocarcinoma located in their rectum or sigmoid. This group was divided into 4 subgroups: $\mathrm{A}, \mathrm{B}, \mathrm{C}$, and D, depending on the degree of the severity of the above-mentioned cancer according to Dukes' classification (Table 1). All the patients had normal BMI (there were no subjects with obesity).

The control group consisted of 20 healthy volunteers ( 8 women, 12 men; mean age for the entire group was $61.2 \pm 13.9$ years) with the negative family history of CAC. All participants had not been smoking tobacco or taking any vitamins or microelement supplements for at least 6 months before the start of the research.

The clinical diagnosis was performed in accordance with the following pattern: a) physical examination and taking medical history; b) examination of large intestine (rectoscopy and/or colonoscopy with collection of samples

Table 1. Classification of participating patients with colonic adenocarcinoma (CAC) into subgroups according to Dukes' classification

\begin{tabular}{|l|c|c|c|c|}
\hline \multicolumn{1}{|c|}{ Division data } & \multicolumn{4}{|c|}{$\begin{array}{r}\text { Degree of clinical severity of CAC according } \\
\text { to Dukes' classification }\end{array}$} \\
\hline Subgroup symbols & A & B & C & D \\
\hline Number of patients & 34 & 17 & 30 & 21 \\
\hline Women : men & $15: 19$ & $6: 11$ & $12: 18$ & $8: 13$ \\
\hline Mean age [years] & $63.1 \pm 12.8$ & $65.9 \pm 9.4$ & $65.9 \pm 9.0$ & $62.6 \pm 10.2$ \\
\hline
\end{tabular}


for histopathological assessment; transanal ultrasound examination); c) imaging examination in search of distant metastases (ultrasound examination and/or CT scan of abdominal cavity, chest X-ray scan). Based on the above diagnostic tests, all subjects were preliminarily qualified for surgical treatment. In most cases surgical resection of the tumor was performed.

Tissue samples obtained during the surgeries were subject to histopathological assessment. The results constituted the basis for classifying patients into particular groups with respect to the degree of severity of the disease. But, in some patients, the extent of intrasurgically detected neoplastic proliferation was a cause of disqualification from surgical treatment (cases recognized as a non surgical).

\section{Blood and plasma sampling}

The analyzed material was blood $(5.0 \mathrm{~mL}$ from each patient) drawn on an empty stomach from the basilic vein by means of Vacuette (heparinised tube) system. The material was temporarily stored in a refrigerator $\left(4^{\circ} \mathrm{C}\right)$, and within no later than $2 \mathrm{~h}$ from sample collection centrifuged for $10 \mathrm{~min}$ in a MPW 360 centrifuge (Mechanika Precyzyjna, Warszawa, Poland) at $650 \times$ g. Separated portions of plasma were moved to Eppendorf test tubes and stored at $-80^{\circ} \mathrm{C}$ until the material was collected from all participants.

\section{Biochemical determinations}

The described further assays were carried out immediately after defrosting the collected samples. Spectrophotometric measurements were performed by means of a Lambda 14 P (Perkin Elmer, Überlingen, Germany) apparatus.

The Total Antioxidant Status Kit (Randox, Crumlin, United Kingdom), based on Miller et al. method, was used to assay TAC in blood plasma. ${ }^{7}$ In accordance with the assay procedure, a synthetic water-soluble analogue of vitamin E (Trolox catalogue No. 238813-1G, Sigma-Aldrich, St. Louis, USA) was used as a standard. After performing the steps specified by the producer of the kit and carrying out the spectrophotometric measurements at $600 \mathrm{~nm}$, the resultant values were expressed in terms of $\mathrm{mmol} / \mathrm{L}$ Trolox equivalents.

The content of $\mathrm{C}=\mathrm{O}$ groups in plasma proteins was assayed in accordance with Levine et al. method. ${ }^{8}$ Proteins were precipitated from the analyzed samples with $10 \%$ trichloroacetic acid and the separated sediments were incubated in $37^{\circ} \mathrm{C}(1 \mathrm{~h})$ with $0.2 \%$ solution of 2 ,4-dinitrophenylhydrazine in $2 \mathrm{M} \mathrm{HCl}$ and dissolved in guanidine hydrochloride. After carrying out the spectrophotometric measurements at $370 \mathrm{~nm}$ and performing the steps specified by the recalculation method, the resultant values were expressed in terms of $\mathrm{nmol} / \mathrm{mg}$ protein.

\section{Ethics}

The study was conducted in accordance with the Declaration of Helsinki and with principles of the Good Clinical Practice. The study protocol was approved by the Bioethical Commission of the Medical University of Lodz, Poland (decision No. RNN/586/07/KB). All participants agreed to take part in the tests voluntarily and gave their consent in writing.

\section{Statistical analysis}

The results were statistically analyzed by means of STATISTICA v. 6.0 software (StatSoft, Tulsa, USA). Results obtained in different groups of patients were compared to those of healthy individuals as well as between groups. Compliance of parameters with normal distribution was assessed using the Shapiro-Wilk test. Most results did not present normal distribution (analysis of variance ANOVA, Kruskal-Wallis test by rank); therefore, variables were compared between groups using the nonparametric Dunn-Bonferroni method. The level of statistical significance for the results of all tests was assumed to be $\mathrm{p}<0.05$. Evaluation of correlations between the results of TAC and $\mathrm{C}=\mathrm{O}$ groups assays was calculated using Spearman's rank correlation coefficient $r_{s}$. Based on the obtained analytical data, a trend (regression) line was established between the sets of both types of the assayed parameters.

\section{Results}

Results of TAC assays performed in the plasma of patients with CAC at various stages of clinical severity (according to Dukes' classification), as well as in people from the control group (healthy volunteers) are graphically demonstrated in Fig. 1a.

It was found that in all stages of severity of the tumor, the values of plasma TAC were statistically significantly lower $(1.783 \mathrm{mmol} / \mathrm{L}$ in the control group vs $1.191 \mathrm{mmol} / \mathrm{L}$ in group $\mathrm{A}, 1.07 \mathrm{mmol} / \mathrm{L}$ in group $\mathrm{B}, 0.931 \mathrm{mmol} / \mathrm{L}$ in group $\mathrm{C}$, and $0.899 \mathrm{mmol} / \mathrm{L}$ in group $\mathrm{D} ; \mathrm{p}<0.05$ ).

At the same time, it was observed that the degree of decrease in the results for patients with CAC was becoming deeper with the progression of the disease. Differences between subgroups A and B, as well as B and C were statistically significant, while the difference between subgroups $\mathrm{C}$ and $\mathrm{D}$ did not show this significance.

The results of assays of $\mathrm{C}=\mathrm{O}$ groups content in plasma proteins of patients with $\mathrm{CAC}$ at all stages of severity of the disease in accordance with Dukes' classification, as compared to the control group, are presented in Fig. 1 b.

Statistically, significantly $(\mathrm{p}<0.05)$ higher values of $\mathrm{C}=\mathrm{O}$ groups in plasma proteins were observed at all severity stages of the cancer in comparison with the control group. It was found that the above mentioned values of the results 
were increasing in patients with CAC to an extent which reflected the advancement of the disease $(0.496 \mathrm{nmol} / \mathrm{mg}$ protein vs $0.57 \mathrm{nmol} / \mathrm{mg}$ protein in group A, $0.689 \mathrm{nmol} /$ mg protein in group $B, 0.804 \mathrm{nmol} / \mathrm{mg}$ protein in group $C$, and $1.054 \mathrm{nmol} / \mathrm{mg}$ protein in group $\mathrm{D}$. The differences between the results obtained in all subgroups of participating patients were statistically significant.

Observations on the decrease in plasma TAC values progressing with the stages of severity of CAC, as well as the increase in $\mathrm{C}=\mathrm{O}$ groups content in plasma proteins prompted us to analyze the mutual correlation between alternations of these 2 parameters. As a result of the performed analysis, a negative correlation was noted between values of plasma TAC and the content of $\mathrm{C}=\mathrm{O}$ groups in plasma proteins $\left(\mathrm{r}_{\mathrm{s}}=-0.566 ; \mathrm{p}<0.05\right)$ (Fig. 2).

\section{Discussion}

For many years now, TAC assays in clinically collected material (usually blood plasma) have had an acknowledged position in studies with patients suffering from diseases with oxidative stress, including cancer. This is due to the fact that they provide a comprehensive view of the status of the body's anti-oxidative defense system. Our own assays of TAC revealed a weakening of this system in patients with CAC. As it has been mentioned

a

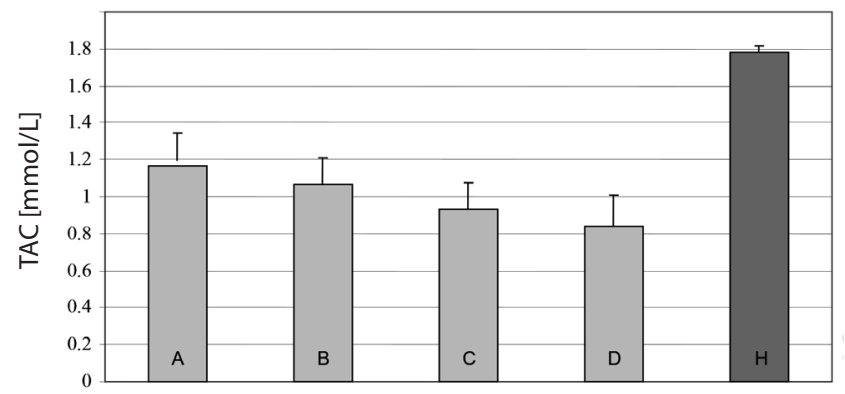

subgroups of patients according to Dukes' classification to tumors

b

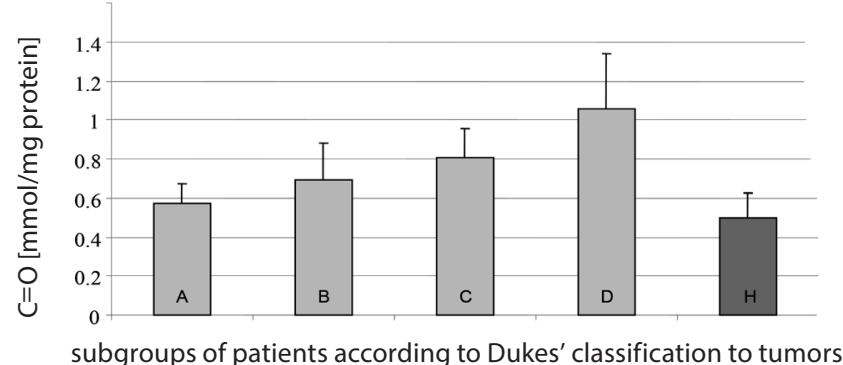

Fig. 1. Mean values of assays

$\mathrm{a}$ - total antioxidant capacity (TAC); b - contents of carbonyl $(C=0)$ groups, performed in patients with various degrees of severity of the tumor. Mean values of both parameters for all subgroups were significantly different at $\mathrm{p}<0.05$ vs control group $\mathrm{H}$ (healthy). in the Results section, values of TAC in subsequent stages of CAC severity (according to Dukes' classification) were statistically significantly lower in comparison with the control group. The results of this study have been fully confirmed by the data presented in the references.

Brodzki et al. noted decreased values of TAC in animals with malignant perianal tumors. ${ }^{9}$ The same observations were made by Gupta et al. in patients with head and neck squamous cell carcinoma. These findings show that oxidative stress is elevated in cancer patients as evidenced by elevated levels of lipid peroxidation products - malondialdehyde (MDA). ${ }^{10}$ In the study conducted by Subramanyam et al., the decreased levels of glutathione peroxidase activity and total antioxidant capacity, and increased malondialdehyde, glutathion reductase, were observed in cervical cancer patients when compared to healthy controls. ${ }^{11}$ Decreased levels of TAC in patients with lung cancer, correlating with oxidative damages of proteins, were acknowledged by Erhola et al. ${ }^{12}$ Similar observations were made by Hietanen et al. with regard to patients suffering from breast or prostate cancer, as well as colorectal carcinoma (CC), which was especially significant compared to the results of the research described herein. ${ }^{13}$ Equally significant for the comparison of the obtained results were the studies carried out by Czeczot et al., who noted the decrease in TAC levels with the advancement of CC severity. ${ }^{14}$ The weakening of the body's antioxidative status in accordance with the severity of cases was also observed by Saygili et al., but this research was restricted to stages B and C according to Dukes' classification (patients at stages $\mathrm{A}$ and D were not included in the research). ${ }^{15}$ However, in that case, the authors did not assay TAC values, but only the chosen antioxidants: concentrations of glutathione and activities of dependent enzymes. Results of a study conducted by Kocot et al. indicated that in stages I, II and III of colorectal cancer, the total antioxidant status value was increased in tumor tissue as compared to healthy tissue and markedly decreased in stage IV in contrast to the other stages of the disease. ${ }^{16}$

The references also describe studies on assays of the destructive influence of ROS on the macroparticles of cells in clinical material, which are equally important for the research on carcinogenesis. As it was already pointed out, the most commonly analyzed were the products of lipid peroxidation, generally MDA and oxidative modification of DNA, especially 8-OHdG (8-hydroxy2'-deoxyguanosine). ${ }^{17,18}$ Much less common were assays of products of the adverse influence of ROS on proteins, even though proteins in various forms (including enzymes) are the main component of the body. As a result, the correlations between oxidative damages of proteins and the process of carcinogenesis have not been sufficiently explained. Stadtman et al. suggested, for example, that the abovementioned damages may be in vivo more biologically significant than lipid damages but, unfortunately, there are too few studies documenting this. ${ }^{19}$ 


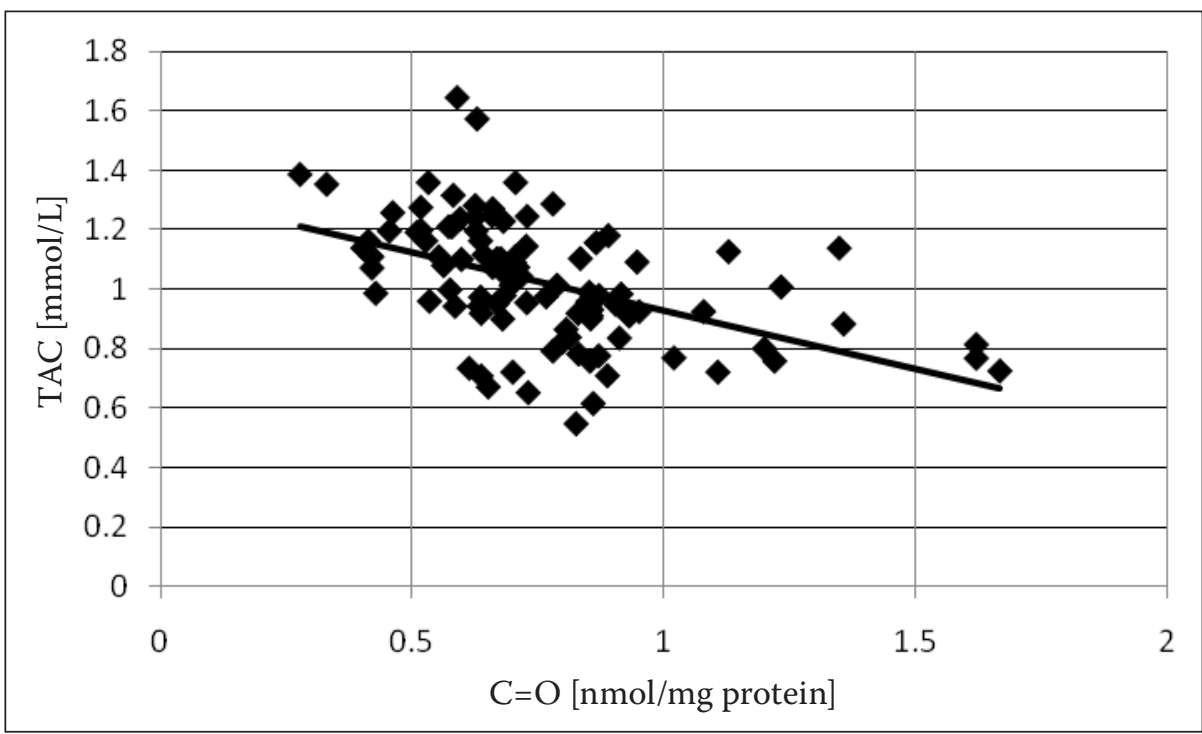

Fig. 2. Correlation between assayed values of total antioxidant capacity (TAC) and contents of carbonyl $(C=O)$ groups: Correlation coefficient rs and trend line

An important opinion on the oxidative damages of proteins was expressed by us at the beginning of this paper. It was said that for the evaluation of the effects of ROS influence on proteins, the most reliable are the assays of contents of $\mathrm{C}=\mathrm{O}$ groups. These groups are components of aldehydes or ketones, which are formed as a result of ROS oxidation of proteinaceous amino acid residues with free groups $-\mathrm{NH}_{2},-\mathrm{CONH}_{2}$ or $-\mathrm{OH}$, as well as during the splitting of polypeptide chains. ${ }^{20}$ Formation of these carbonyl derivatives of proteins takes place during a reaction with ROS earlier than in the case of other products, which supports the opinion on the reliability of $\mathrm{C}=\mathrm{O}$ group assays quoted above and convinced us to include them in the study.

Results of our assays of $\mathrm{C}=\mathrm{O}$ group contents in plasma proteins, as presented in the Results section, were significantly higher in patients with CAC than in the control group. Moreover, the increase of this parameter was observed in each subsequent degree of CAC severity (according to Dukes' classification). Other researchers obtained analogous data with regard to other tumors.

Renke et al. noted that contents of $\mathrm{C}=\mathrm{O}$ groups in plasma proteins of children with several types of malignant tumors were twice as high as in healthy children. ${ }^{21}$ Yilmaz et al. observed significantly elevated values of this parameter in patients with bladder cancer and noted its additional increase in the invasive form, although the differences were not statistically significant. ${ }^{22}$ The most important data for comparison with our results was obtained by Chang et al., who observed elevated contents of $\mathrm{C}=\mathrm{O}$ groups in plasma proteins in $\mathrm{CC}$ patients, with a simultaneous decrease of activities of antioxidative enzymes and contents of vitamins $\mathrm{C}$ and $\mathrm{E} .{ }^{23}$ The same authors noted that patients with $\mathrm{CC}$ had a lower concentration of MDA in their plasma than healthy people, which indicates a greater sensitivity of assays of protein $\mathrm{C}=\mathrm{O}$ groups for the evaluation of oxidative damages caused by ROS. Avinash et al. observed a significant increase in advanced oxidation protein products (AOPP), percent hemolysis (that indirectly indicates the degree of membrane damage secondary to lipid peroxidation), and a highly significant increase in globulin in colorectal carcinoma. Results of this experiment demonstrated oxidative stress, decreased antioxidant status, and secondary inflammatory response in colorectal carcinoma. ${ }^{24}$

The results of our study demonstrate the existence of the increased oxidative stress in patients with CAC. It seems, however, that it is an effect of the increased severity of the neoplasm rather than its cause. Such a conclusion seems to be confirmed by Erhola et al., who observed an improvement of competence markers of the body's anti-oxidative defense system after resection of the tumor. ${ }^{12}$ According to these authors, this was due to the elimination of the oxidative stress caused by the tumor. A similar opinion was presented by Hamada et al., who studied mice with breast cancer, as well as by Lusini et al., who examined patients with kidney cancer. ${ }^{25,26}$ These conclusions appear to be justifiable by the complexity of mechanisms regulating the processes of pro- and anti-oxidative balance. ${ }^{27}$

There are 2 interesting theories attempting to explain the shift of the balance in the prooxidative direction in patients with advanced tumors. The first is based on cancer-related nutritional disorders which are significant for these stages of tumors and which result in vomiting, lack of appetite or even anorexia. They prevent sufficient supply of anti-oxidative nutrients, indispensible for the elimination of excessive amounts of ROS. This effectively leads to oxidative stress. ${ }^{28}$ The other theory assumes that the developing tumor progressively stimulates the body's immune system by increasing the production of pro-inflammatory cytokines and intensifies the inflammatory reaction. The increased activation of leukocytes intensifies the production of ROS and, as a result, causes oxidative stress. ${ }^{29}$ This theory is confirmed by the increase in inflammatory markers (concentrations of CRP and IL- 6 in plasma), correlating with the severity of the cancer, while the connection between chronic inflammation and oxidative stress is recognized as one of the "release mechanisms" of carcinogenesis. ${ }^{28}$

The conclusion from the first theory is of major importance for the research, i.e., an insufficient supply of nutrient antioxidants, including anti-oxidative vitamins, is weakening the cells' shield against ROS, which may lead, among others, to the initiation and stimulation of carcinogenesis. 
Therefore, the opinions arising from epidemiological studies become obvious - a diet rich in these vitamins lowers the risk of developing various cancers, including CAC. ${ }^{30,31}$ These substances prevent the transformation of cells and the proliferation and invasion of the existing tumors. The systemic effect of their use is the strengthening of the anti-oxidative defense system (that is why the study included exclusively subjects who did not take any anti-oxidative supplements). ${ }^{31}$ This is a rational argument for systematic consumption of fruit and vegetables rich in the abovementioned vitamins as a preventative strategy against $\mathrm{CAC}$, as well as for supplementing people from the groups of increased risk with relevant preparations as a form of chemoprevention, or as an adjuvant therapy for patients with CAC.

\section{References}

1. Wojciechowska U, Didkowska J, Zatoński W. Nowotwory złośliwe w Polsce w 2008 roku. [Cancer in Poland in 2008.] Warszawa: Centrum Onkologii, Instytut im. M. Skłodowskiej-Curie; 2010:20-21.

2. Regula J, Rupinski M, Kraszewska E, et al. Colonoscopy in colorectal-cancer screening for detection of advanced neoplasia. N Engl J Med. 2006;355:1863-1872.

3. López-Alarcóna C, Denicola A. Evaluating the antioxidant capacity of natural products: A review on chemical and cellular-based assays. Anal Chim Acta. 2013;763:1-10.

4. Afanas'ev I. Reactive oxygen species signaling in cancer: Comparison with aging. Aging Dis. 2011;2:219-230.

5. Liu J, Zhang X, Yang F, Li T, Wei D, Ren Y. Antimetastatic effect of a lipophilic ascorbic acid derivative with antioxidation through inhibition of tumor invasion. Cancer Chemother Pharmacol. 2006;57:584-590.

6. Błauż A, Pilaszek T, Grzelak A, Dragan A, Bartosz G. Interaction between antioxidants in assays of total antioxidant capacity. Food Chem Toxicol. 2008;46:2365-2368.

7. Miller NJ, Rice-Evans C, Davies MJ, Gopinathan V, Milner A. A nove method for measuring antioxidant capacity and its application to monitoring the antioxidant status in premature neonates. Clin Sci. 1993;84:407-412.

8. Levine RL, Garland D, Oliver CN. Determination of carbonyl content in oxidatively modified proteins. Methods Enzymol. 1990;186: 464-478.

9. Brodzki A, Brodzki P, Tatara MR, Kostro K. Total antioxidative capacity and zinc concentration in dogs suffering from perianal tumours. Bull Vet Inst Pulawy. 2015;59: 417-423.

10. Gupta A, Bhatt ML, Misra MK. Lipid peroxidation and antioxidant status in head and neck squamous cell carcinoma patients. Oxid Med Cell Longev. 2009;2:68-72.

11. Subramanyam D, Subbaiah KV, Rajendra W, Lokanatha V. Serum selenium concentration and antioxidant activity in cervical cancer patients before and after treatment. Exp Oncol. 2013;35(2):97-100.

12. Erhola M, Nieminen MM, Kellokumpu-Lehtinen P. Effects of surgical removal of lung cancer on total plasma antioxidant capacity in lung cancer patients. J Exp Clin Cancer Res. 1998;17:219-225.

13. Hietanen $\mathrm{E}$, Bartsch H, Béréziat JC. Diet and oxidative stress in breast, colon and prostate cancer patients: A case-control study. Eur J Clin Nutr. 1994;48:575-586.

14. Czeczot H, Skrzycki M, Podsiad M, Gawryszewska E, Nyckowski P, Porembska Z. Antioxidant status of patients with primary colorectal cancer and liver metastases of colorectal cancer. Pol Merk Lek. 2005;18:58-61.

15. Saygili El, Akcay T, Konukoglu D, Papila C. Glutathione and glutathione-related enzymes in colorectal cancer patients. J Toxicol Environ Health A. 2003;14:411-415.

16. Kocot J, Kiełczykowska M, Dąbrowski W, Piłat J, Rudzki S, Musik I. Total antioxidant status value and superoxide dismutase activity in human colorectal cancer tissue depending on stage of the disease: A pilot study. Adv Clin Exp Med. 2013;22(3):431-443.
17. Ayala A, Muñoz MF, Argüelles S. Lipid peroxidation: Production, metabolism, and signaling mechanisms of malondialdehyde and 4-hydroxy-2-nonenal. Oxid Med Cell Longev. 2014;2014:360438.

18. Valavanidis A, Vlachogianni T, Fiotakis C. 8-Hydroxy-2'-deoxyguanosine (8-OHdG): A critical biomarker of oxidative stress and carcinogenesis. J Environ Sci Health CEnviron Carcinog Ecotoxicol Rev. 2009;27:120-139.

19. Stadtman ER, Berlett BS. Reactive oxygen-mediated protein oxidation in aging and disease. Drug Metab Rev. 1998;30:225-243.

20. Ponczek MB, Wachowicz B. Interaction of reactive oxygen and nitrogen species with proteins. Postepy Biochem. 2005;51:140-145.

21. Renke J, Popadiuk S, Korzon M, Bugajczyk B, Woźniak M. Protein carbonyl groups' content as a useful clinical marker of antioxidant barrier impairment in plasma of children with juvenile chronic arthritis. Free Radic Biol Med. 2000;29:101-104.

22. Yilmaz IA, Akçay T, Cakatay U, Telci A, Ataus S, Yalcin V. Relation between bladder cancer and protein oxidation. Int Urol Nephrol. 2003;35:345-350.

23. Chang D, Wang F, Zhao YS, Pan HZ. Evaluation of oxidative stress in colorectal cancer patients. Biomed Environ Sci. 2008;21:286-289.

24. Avinash SS, Anitha M, Vinodchandran, Rao GM, Sudha K, Shetty BV. Advanced oxidation protein products and total antioxidant activity in colorectal carcinoma. Indian J Physiol Pharmacol. 2009;53:370-374.

25. Hamada J, Nakata D, Nakae D. Increased oxidative DNA damage in mammary tumor cells by continuous epidermal growth factor stimulation. J Nat/ Cancer Inst. 2001;93:214-219.

26. Lusini L, Tripodi SA, Rossi R. Altered glutathione anti-oxidant metabolism during tumor progression in human renal-cell carcinoma. Int J Cancer. 2001;91:55-59.

27. Dawane JS, Pandit VA. Understanding redox homeostasis and its role in cancer. J Clin Diagn Res. 2012;6(10):1796-1802.

28. Mantovani G, Macciò A, Madeddu C. Quantitative evaluation of oxidative stress, chronic inflammatory indices and leptin in cancer patients: Correlation with stage and performance status. Int J Cancer. 2002;98:84-91.

29. Mantovani G, Macciò A, Madeddu C. Antioxidant agents are effective in inducing lymphocyte progression through cell cycle in advanced cancer patients: Assessment of the most important laboratory indexes of cachexia and oxidative stress. J Mol Med. 2003;81:664-673.

30. Leung EY, Crozier JE, Talwar D. Vitamin antioxidants, lipid peroxidation, tumour stage, the systemic inflammatory response and survival in patients with colorectal cancer. Int J Cancer. 2008;123:2460-2464.

31. Guan F, Li G, Liu AB. $\delta$ - and $\gamma$-tocopherols, but not a-tocopherol, inhibit colon carcinogenesis in azoxymethane-treated F344 rats. Cancer Prev Res. 2012;5:644-654. 